\title{
Research on the Avoidance of Moral Hazard in Higher Education Evaluation of China Under Multi-agent Mode
}

\author{
Yang Chun Sun, An Qi Xu \\ Graduate School of Education, Dalian University of Technology, Dalian, China \\ Email address: \\ sunyangchun2003@163.com (Yang Chun Sun), uanqi1993@163.com (An Qi Xu)
}

\section{To cite this article:}

Yang Chun Sun, An Qi Xu. Research on the Avoidance of Moral Hazard in Higher Education Evaluation of China Under Multi-agent Mode. Education Journal. Vol. 8, No. 6, 2019, pp. 259-265. doi: 10.11648/j.edu.20190806.14

Received: August 27,2019; Accepted: September 12, 2019; Published: September 27, 2019

\begin{abstract}
The education evaluation agencies will undertake education evaluation task and will form principal-agent relationships with the governments with the separation reform of supervision, running and evaluation in China. Because of bounded rationality and information asymmetry, it was already a big problem to avoid the moral hazard of an education evaluation agency in a principal-agent relationship involving only one principal and one agent. In reality, the principal-agent relationship is often more complicated. Of particular concern is that the situation of "one principal-multiple agents" in the evaluation of higher education has emerged. The coexistence of "multiple" education evaluation agencies, such as the official agencies, the semi-official agencies, the agencies affiliated with the university, and the third-party agencies, has taken shape. By using critical discourse analysis, this study attempts to argue that avoiding the moral hazard of higher education evaluation under the "multi-agent" mode becomes a research issue that must be squarely addressed. The paper concluded that in "multi-agent" mode, although the possibility of implied moral hazard in higher education evaluation increases, if the "relative performance" evaluation mechanism can be understood and effective measures can be taken, not only will it not lead to the consequences of moral hazard being more difficult to avoid, but it will greatly enhance the effectiveness of the avoidance of moral hazard. The conclusion has important reference significance on how to effectively use the "multi-agent" mode to avoid the moral hazard of higher education evaluation.
\end{abstract}

Keywords: Moral Hazard, Multi-agent, Education Evaluation

\section{Introduction}

With the separation reform of supervision, running and evaluation in China, the education evaluation agencies will undertake education evaluation task and will form a principal-agent relationship with the government. Extensive research has shown that it has already a big problem to ensure that the specific education evaluation agency can conduct evaluation tasks fairly and openly and avoid opportunistic behaviors on behalf of the public interest in the previous principal-agent relationship of "a principal (government)-an agent (single education evaluation agency)" because of bounded rationality and information asymmetry $[1,2]$.

However, previous studies have not recognized that there were often more than one higher education evaluation agencies may act as agents, especially, with the separation reform of supervision, running and evaluation the education evaluation rights transformed from the government to the "social agencies", the situation of "a principal (government)-multiple agents (multiple education evaluation agencies)" was gradually presented. As we all know, it has been a long time since the government commissioned education evaluation to "the official, the semi-official, and the professional agencies of higher education". However, in 2010, the "separation reform of supervision, running and evaluation" was first proposed in the form of an official document in the "National Medium- and Long-Term Education Reform and Development Plan (2010-2020)" in China, and the third-party education evaluation agencies were set up one after another. Subsequently, the government began to form principal-agent relationships with "multiple educational evaluation agencies". For example, Beijing, Qingdao, Wenzhou and other places in China have launched the "The Third-party Agency List".

1 Beijing, China announced the "Interim Measures of the Education Supervision 
Beijing has included 15 educational evaluation agencies in the "The Third-party Agency List" when Qingdao has included 27. Moreover, they clearly stipulated that the government must select the evaluation agencies from the "List" when entrusting third-party agencies, which indicated that these local governments have "signed" with a number of third-party education evaluation agencies to undertake education monitoring and evaluation task. As a result, the situation in which the government and the "multiple" higher education evaluation agencies jointly carried out education evaluation has taken shape. Multi-agent mode of "a principal (government)-multiple agents (multiple education evaluation agencies)" has gradually entered the practice of higher education evaluation.

So, how could the government "manage" multiple education evaluation agencies when facing a multi-agent relationship of "one principal-multiple agents"? How can we ensure that "agencies with high quality" become the ultimate "agents" and complete the government-appointed evaluation tasks in a fair and equitable manner so as to avoid the possible moral hazard of "rent-seeking and low-level efforts" [3]? There is an urgent need to answer and resolve these problems.

This study points out that the possibility of implied moral hazard in higher education evaluation under "multi-agent" mode increases, however, if the "relative performance" evaluation mechanism under the "multi-agent" mode can be understood and effective measures can be taken, not only will it not lead to the consequences of moral hazard being more difficult to avoid, but it will greatly enhance the effectiveness of the avoidance of moral hazard. The findings are derived from the Multi-agent Theory.

\section{What Is Multi-agent Theory}

Multi-agent Theory was the product of the development of Principal-agent Theory to a certain stage. Principal-agent Theory has been greatly developed since the 1980s. It was at that time that Multi-agent Theory was produced as an important branch. Holmstrom (1982), Sappinngton and Demski (1983), Wookherjee (1984) are the main researchers. Multi-agent mode that expanded the number of agents from "one" to "multiple" based on the framework of "one principal-one agent" was proposed in relation to the traditional "one agent" mode. Therefore, the principal and "multiple agents" formed "single-to-multiple" relationships. There were "multiple agents" who interact with each other, which was the biggest difference between "multi-agent" mode and "single agent" mode.

Multi-agent mode was the choice made when the principal faced a complex and important commissioning task to ensure that it could be completed efficiently. Principal-agent

Office of the Beijing Municipal People's Government on Entrusting Third-Party Institutions to Conduct Educational Evaluation and Monitoring" on May 30, 2016 and included 15 educational evaluation agencies in the "The Third-party Agency List". Qingdao, China announced the "Measures for the Evaluation of Entrusted Third-Party Institutions in Qingdao (Interim)"'on November 28, 2017 and included 27 educational evaluation agencies in the "The Third-party Agency List". relationship is too "simple and ideal" because it only considered a situation including single principal, single agent, and single task $[4,5]$. When the task being entrusted become "complex and important" $[6,7]$, it is necessary to delegate the task to multiple agents, forming a "single-to-many" relationship form, with full participation and association of multiple agents working hard to complete the task smoothly and efficiently [8].

Multi-agent Theory has a major impact on the research of "cooperative governance" of the organization, and has been introduced and discussed in many fields in China such as "corporate governance" [9], "marketing system" [10] and "project cooperation" [11].

\section{Multi-agent Mode in Higher Education Evaluation}

After the evaluation power were separated from management, several education evaluation agencies began to undertake evaluation task together. These evaluation agencies in China mainly include four categories: official agencies, semi-official agencies, agencies affiliated with the universities, and the third-party agencies (see Table 1).

Table 1 presents an overview of multiple higher education evaluation agencies in China. The participation of multiple agencies in the higher education evaluation is based on the need of importance and complexity for higher education evaluation. Education evaluation is an indispensable key link in the education quality assurance system as well as the core work related to education development. Its importance is self-evident. Moreover, the quality evaluation of higher education is also a complex project which is manifested by the increasing diversity of evaluation concepts for higher education quality, the difficulty in determining and unifying evaluation indicators as well as the difficulty in quantifying evaluation data. It is precisely because the higher education evaluation is so important and quite complicated that it is necessary for the government to entrust a number of evaluation agencies as agents to participate in the evaluation of higher education.

So what kind of mode do these higher education evaluation agencies act as agents to participate in higher education evaluation? How are their specific work structures presented? As shown in figure 1 and figure 2, there are two kinds of working forms in the "multi-agent" mode. The first is the "separate form" in which a holistic work is divided into multiple partial tasks and assign them to multiple agents. Each agent gives full play to their respective advantages and completes the principals in different fields, at different stages and different levels; The second is the "synchronal form" that many agents undertake one same task in a synchronal way. At this time, the given task does not need to be divided, and multiple agents perform from different dimensions simultaneously. Similarly, the multi-agent mode of education evaluation also appears in two forms. One is to divide an education evaluation task into different stages and different 
parts (see figure 1), which are undertaken by different evaluation agencies. For example, the undergraduate education evaluation is mainly undertaken by Higher Education Evaluation Center of the Ministry of Education while the postgraduate evaluation is mainly carried out by the Academic Degrees \& Graduate Education Development Center. This form reflects typical "Separate agents" mode of multiple higher education evaluation agencies; The other is to hand over the same task to multiple higher education evaluation agencies for simultaneous evaluation (see figure 2) For example, Shanghai Ranking, Wuhan University, cuaa. net and many other agencies are all engaged in university rankings, which reflects the "synchronal agents" mode.

Table 1. Multiple higher education evaluation agencies in China.

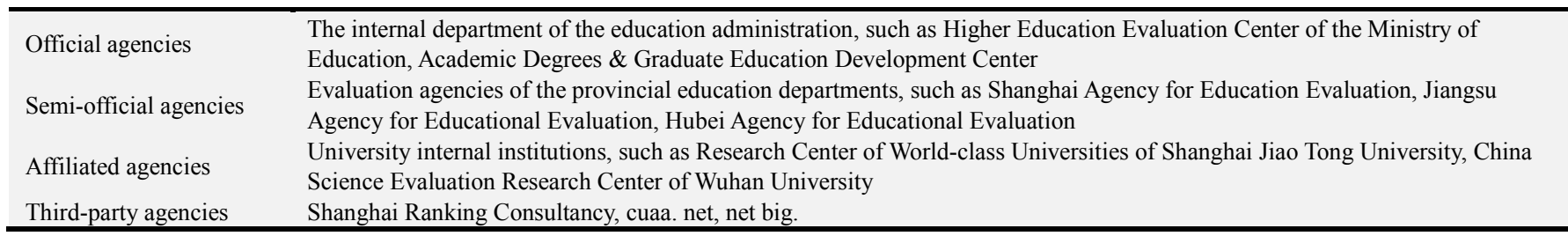

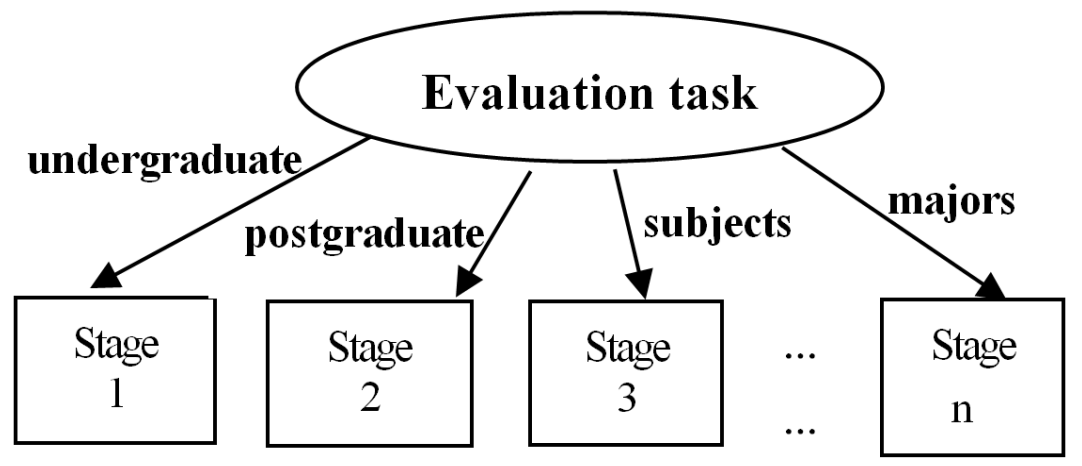

Figure 1. Separate agents in Higher Education Evaluation.

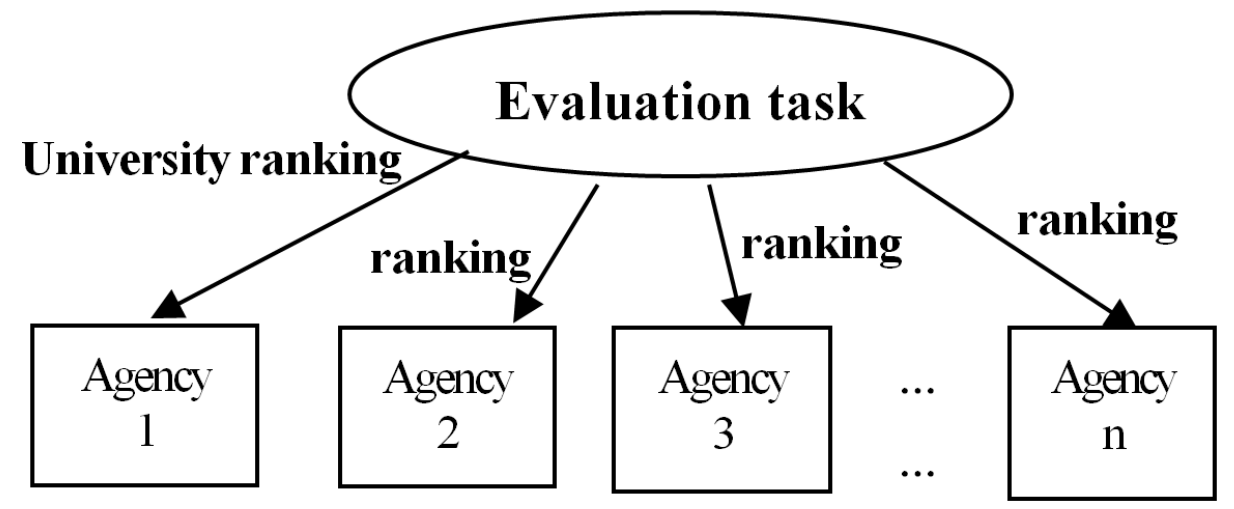

Figure 2. Synchronal agents in Higher Education Evaluation.

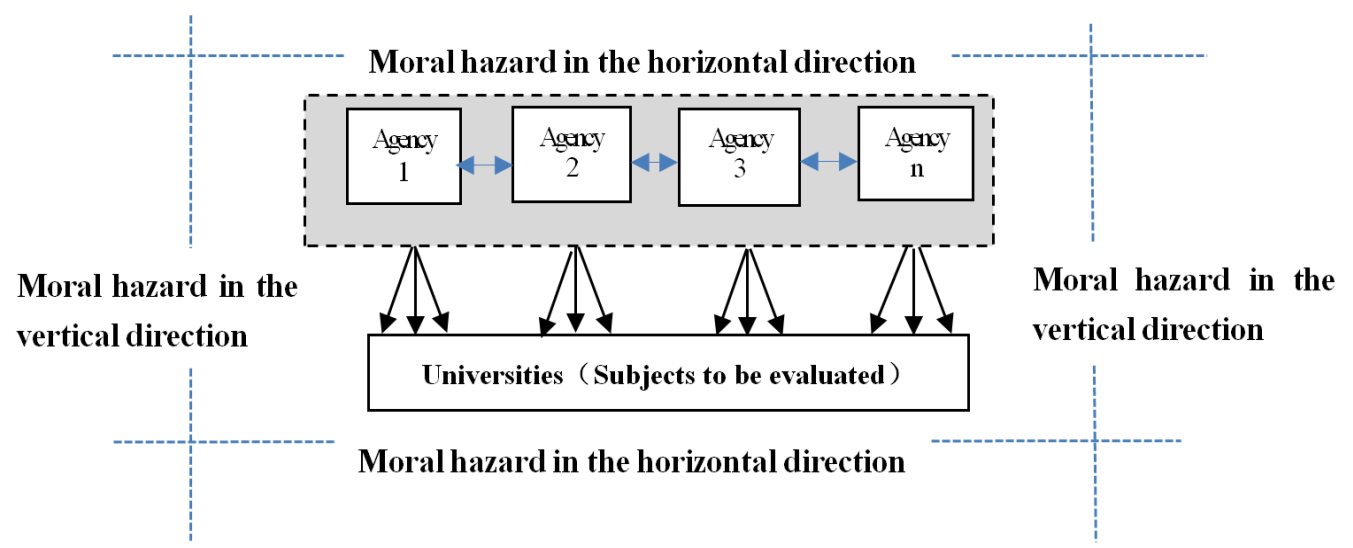

Figure 3. The manifestation of moral hazard in higher education evaluation in multi-agent mode. 
Compared with the case of single agent, the principal-agent relationship in the "multi-agent" mode has been extended both "vertically and horizontally". In the "vertical" direction, the principal and each agent form a principal-agent relationship separately, thereby forming a plurality of principal-agent relationships; In the "horizontal" direction, all agents can also be referenced and compared.

\section{Moral Hazard Forms that may Be Generated in Higher Education Evaluation in the "Multi-agent" Mode}

The term "moral hazard" refers to the danger of "People engaged in economic activities making opportunistic behaviors in order to maximize their own interests instead of being conducive to others" [12]. In "multi-agent" mode, implied moral hazard behaviors of multiple higher education evaluation agencies during their working process have increased significantly (see Figure 3), both the increase in the amount of "quantity" in the vertical direction and the emergence of new "types" in the horizontal direction.

\subsection{Multiple Evaluation Agencies may Generate Moral Hazard of "Rent-seeking” from Universities}

Previous studies have explored the single agent case that only one higher education evaluation agency acted as an agent When a university was looking for the target of collusion and rent-seeking, only one agency can be selected, and the moral hazard generated between the university and the specific agency; Therefore, the government only need to supervise the only one higher education evaluation agency. However, in multi-agent mode, the government has selected a number of higher education evaluation agencies as agents to evaluate education quality. Each agency will be the target of rent-seeking and collusion for universities, which may result in more rent-seeking and collusion behaviors.

\subsection{Multiple Evaluation Agencies may Generate Moral Hazard of "Low Effort Level"}

The term "effort level" refers to an indicator of the degree to which an agent pays attention to the work as well as the cost paid by the agent. If the evaluation agency has a high level of efforts, it will contribute to the evaluation work actively and complete the evaluation tasks assigned by the government earnestly; Otherwise, it will be perfunctory and less energetic, and then manifested as opportunistic behaviors such as "negative absenteeism and low-level efforts". Unlike the "single agent" mode that only one evaluation agency may generate moral hazard of "low effort level", each agency in the multi-agent mode has the potential to generate moral hazard of low-level effort.

\subsection{Multiple Evaluation Agencies may Generate a New Type of Moral Hazard of "Peer Collusion"}

If the above two kind of moral hazard behaviors are increase in the "quantity" in the multi-agent mode, then "peer collusion" [13] is the addition in moral hazard "type". In the "single agent" mode, there is only a vertical principal-agent relationship. The moral hazard of "rent-seeking, collusion, and low-level effort" will just occur between the specific agent and the object being evaluated (universities). However, in the "multi-agent" mode, there may be horizontal "peer collusion" among multiple education evaluation agencies due to the increase number of agents. For example, in order to seek "union rent" from universities, a number of education evaluation agencies jointly united to misrepresent the evaluation data, and combined to cope with the evaluation work passively so as to obtain government's resources in an improper way, which directly undermined the fairness and justice of the education evaluation and jeopardized the public interest, and, blocked the in-depth advancement of the separation reform of supervision, running and evaluation.

\section{The Avoidance Mechanism of Moral Hazard of Higher Education Evaluation in "Multi-agent" Mode}

"Competition mechanism" is the fundamental reason why multiple agents can avoid moral hazard actively. There will be a "Relative Performance" of each agent after comparison because of the "competition". The comparable "relative performance" obtained by "competition" makes it possible for the "multi-agent" evaluation mode to avoid moral hazard more effectively.

Specifically, the work performance of each agent is available because of mutual comparison when multiple agents come to complete a task separately. In other words, the work performance of each agent is a reference for other agents. It can be learned from the Multi-agent Theory that the reason why the multi-agent mode can avoid moral hazard to a certain extent is that it transformed the "absolute performance" of a single agent into the "relative performance" of multiple agents, which makes it possible for the agents to refer and compare with each other, thus making the incentive and supervision of the principal more feasible. More specifically, compared with single agent mode, multi-agent mode is more advantageous for the avoidance of the agents' moral hazard in terms of supervision constraints and incentive mechanisms (see Table 2).

Table 2. Comparison of moral hazard avoidance mechanism in single agent and multiple agents.

\begin{tabular}{lll}
\hline & Single agent & Multiple agents \\
\hline Performance types & Absolute performance & Relative performance \\
Reference \& Comparison & No peer reference and comparison & Peer reference and comparison \\
Incentive ways & Incentives from the principal & Incentives from the principal\& incentives from the agent peers \\
\hline
\end{tabular}




\begin{tabular}{lll}
\hline & Single agent & Multiple agents \\
\hline Supervising ways & "Vertical" supervision from principal & "Vertical" supervision from principal\& "Horizontal" supervision within agents \\
Environment factors & Cannot recognize "noise" & Easy to eliminate "noise" \\
\hline
\end{tabular}

\subsection{Peer Competition can Motivate Higher Education Evaluation Agencies to Obtain Legitimate Profits}

Multi-agent mode can promote "competitive incentives" [14] to obtain legitimate profits. The information asymmetry between the principal and the agent is the main cause of moral hazard. Agents with information advantage will deliberately conceal their behaviors of pursuing power and paying low-level efforts in order to obtain more profits. It is precisely because the relative performance of each agencies can be compared and referenced to each other that whether the evaluation results of each agency are fair depends not only on their own evaluation results, but also on the evaluation results of other evaluation agencies. In order to be better in the comparison, each evaluation agency will work harder than other agencies to produce better evaluation results to obtain more economic resources and reputation resources than other agencies. Just as Holmstrom said, "Linking agent compensation to business performance is the best way to get agents to take the best behavior" [15]. If competitive mechanism is introduced on multiple higher education evaluation agencies, the efforts of any agency can drive the other agencies' efforts, and ultimately each agency will eventually choose high-level efforts. Consequently, in order to get relatively better performance, each higher education evaluation agency will endeavor to finish the evaluation task by adopting more advanced technologies, indicators and methods than competitors to achieve better performance and more profits. Therefore, higher education evaluation will present a fair and objective benign situation.

\subsection{Mutual Supervision can Increase the Difficulty for Higher Education Evaluation Agencies to Implement Opportunistic Behaviors}

Multi-agent mode can form "mutual supervision" to increase the difficulty for evaluation agencies to adopt opportunistic behaviors. When multiple agents' performance is evaluated based on the "relative performance obtained by comparison" [16], and the "rewards and punishments" [17] are implemented on the agent based on the relative performance, principal's supervision on agents' behavior has a "reference" that can be observed to some extent. In this sense, relative performance assessments for multiple evaluation agencies can significantly reduce the cost of monitoring moral hazard compared to the absolute performance assessments of single evaluation agency. As Holmstrom said, "information from peer performance" [18] helped to reduce the information asymmetry between the principal and the agent, thereby reducing the cost of the principal supervising the agents. Under this circumstance, the education evaluation agencies also realized that the moral hazard behaviors of falsely reporting evaluation results can be found easily and may be punished because of the reference from other agencies.
Therefore, in the mode of multiple evaluation agencies, the difficulty of rent-seeking and collusion among higher education evaluation agencies and universities is increasing. In addition, comparison among multiple agents maybe expose some "information" of their behaviors. If one of the evaluation agencies is "perfunctory" to the task, then the low-level effort and "lazy" behavior are also easily detected and identified. In order to avoid being punished, higher education evaluation agencies will choose legitimate behaviors and high-level efforts actively. If there is a corresponding incentive at this time, the probability that the educational evaluation agencies actively choose to avoid moral hazard behavior will increase greatly.

\subsection{Comparisons can Eliminate "Noise" and Motivate Efforts of Multiple Higher Education Evaluation Agencies}

Multi-agent mode can eliminate the "noise" of agents" performance caused by external environment, so as to enhance their effort level. As we all know, the agents' behavioral performance are sometimes brought about by the external and objective environment in which they are located instead of the results of their own ability and efforts. The term "Noise" refers to an objective level of efforts that increase accompanied by external environment (e.g. the improvement of the overall technical level of the society, the prosperity of the market or the situation of the trough) after excluding the performance resulting from the agent's own competence and efforts. The same is true in higher education evaluation. If the evaluation results are greatly affected by the external environment, even these external factors are not recognized, there will be a phenomenon that it is difficult for the government to judge the real quality of the evaluation results; In addition, it may lead to the opportunistic mentality for the evaluation agency to "sit and idle and enjoy the fruits of others' work" in the next round. According to Holmstrom, the performance comparison of multiple agents can filter out the impact of common, external and uncertain environmental factors faced by all agents effectively. In other words, through the comparison of the evaluation results, the "false" performance brought about by the "favorable" or "unfavorable" factors of the environment faced by all evaluation agencies will be automatically offset and filtered out. Therefore, the relative performance evaluation can filter out the environmental "noise", prevent the evaluation agencies from enjoying the "favorable" factors of the environment, and encourage the higher evaluation agencies to choose high-level efforts and produce true and objective evaluation results.

It can be seen that in the multi-agent mode, the moral hazard implicit in higher education evaluation will increase, but the relative performance evaluation mechanism increases the cost and make it easily identified of opportunistic behavior. Hence, the moral hazard of education evaluation can be avoided more effectively. 


\section{Countermeasures on Avoiding Moral Hazard of Higher Education Evaluation Agencies}

Moral hazard of higher education evaluation agencies is a major obstacle to the benign interaction within supervision, running and evaluation. In order to achieve the orderly advancement of separation system, effective measures must be taken to avoid the moral hazard of higher education evaluation agencies so as to achieve linkages among supervision, running and evaluation to improve governance.

\subsection{Cultivating Multiple Higher Education Evaluation Agencies}

Only when there are multiple evaluation agencies can the multi-agent mode form. At the beginning of China's policy of "separation of supervision, running and evaluation", the scale, qualifications and capabilities of higher education evaluation agencies are still not mature. It is necessary to form a set of unique mechanisms for cultivating and selecting higher education evaluation agencies to ensure and promote the growth of them. On the one hand, enhance the professional competence of evaluation agencies. The impartial evaluation results and the in-depth excavation of the quality problems of higher education largely depend on the professional competence of the evaluation agencies. Through nurturing, evaluation agencies can master advanced evaluation concepts and capabilities. Besides, the government should issue policies and regulations to support higher education evaluation, such as reducing tax revenue, urging universities to publish information, and sharing network platform data; On the other hand, standardize the selection process of the evaluation agencies. Clearly assessing agencies' access procedures, organization procedures, and exit procedures is a necessary prerequisite for education evaluation work. The access procedure is an important guarantee for the acquisition of the agencies' evaluation power. The organizational procedure has normative significance for the evaluation agency's working procedures; The exit procedure has important warning significance for the vicious competition, irresponsibility, and disturbance of the evaluation order. The corresponding procedures have a pivotal role in institutional regulation, thereby ensuring a good order for higher education evaluation.

\subsection{Establishing a Competition System for Multiple Higher Education Evaluation Agencies}

The implementation of relative performance evaluation of the work ability and effort level of higher education evaluation agencies is the core recommendation of the Multi-agent Theory to the benign development of higher education evaluation agencies. First, obtain a satisfaction survey of the evaluation results of each agency by establishing a comprehensive evaluation system of satisfaction from experts, universities, and the public, thus forming the relative performance of each evaluation agency. Secondly, performance can be compared and ranked in the form of tournaments to encourage a number of higher evaluation agencies to form innocuous competition. Among them, the relatively high-performance evaluation agencies can receive high compensation paid by the government and continue to sign contracts and also obtain certification from the government, instead, get lower pay and are "eliminated". To sum up, no matter what indicators are used for relative performance evaluation, comparisons and references among multiple higher evaluation agencies can filter common environmental interference and form competition among evaluation agencies, thus avoiding moral hazard to a greater extent.

\subsection{Establishing Mutual Supervision Mechanism Among Multiple Higher Education Evaluation Agencies}

Establishing a mutual supervision mechanism with the participation of a number of higher evaluation agencies to give play to the effectiveness of mutual supervision. Mutual supervision is caused by competition among peers. The establishment of a mutual supervision mechanism expands the intensity of supervision and has a stronger impact on the avoidance of moral hazard. First, standardize the procedures for mutual supervision among multiple evaluation agencies to form an orderly mutual supervision situation, for example, publicizing the basic information, evaluation indicators and evaluation results of various evaluation agencies to ensure mutual understanding among them to provide preconditions for mutual supervision. Second, unblock the feedback channels of mutual supervision. The moral hazard behaviors of all the evaluation agencies can be reported and feedback by other agencies through appropriate channels. Finally, implement the corresponding reward and punishment system according to the results of mutual supervision. Once moral hazard behavior occurred by any evaluation institution, the corresponding cost should be paid according to its consequences. In this way, the real effect of mutual supervision can be brought into play.

In summary, this paper has analyzed the moral hazard of higher education evaluation agencies from the perspective of multi-agent. Compared with the moral hazard prevention under the "single" agent framework, the multi-agent mode increases the peer reference, mutual competition and mutual supervision among the agents, which greatly reduces the difficulty and cost of knowing and supervising the higher education evaluation agencies. Ultimately, the effectiveness of moral hazard avoidance is greatly enhanced. Therefore, the government can try to introduce a multi-agent mode - cultivating and selecting a number of high-quality higher education evaluation agencies, standardizing their operational procedures, and implementing relative performance evaluations to promote healthy competition and mutual supervision mechanisms so that the multi-agent mode can become an effective choice to avoid moral hazard in higher education evaluation. 


\section{Fund Project}

Research on Moral Risk Avoidance of Third-Party Education Evaluation under the Separation System of Supervision, Running and Evaluation, a General National Project of Education Science Planning Project No. BIA170163).

\section{References}

[1] Guan-Yan WANG, Jie YANG. Development of the Third-Party Assessment System for Education Quality Based on Public Trust [J]. Educational Research, 2018 (8): 63-68.

[2] Xiang-Hua WANG, Xi-Lin ZHANG. The Predicament of the Third-party Evaluation of China Higher Education and Its Countermeasures: From the Perspective of New Institutionalism [J]. Journal of Higher Education, 2018 (6): 40-45.

[3] Yang-Chun SUN. Moral Hazard Precaution in University Governance: A Perspective of Residual Rights [J]. Journal of Higher Education, 2018 (2): 22-26.

[4] Bernheim B D, Whinston M D. Common agency [J], Econometrica, 1986, 54 (4): 923-942.

[5] Holmstrom B, Milgrom P. Multi-task principal-agent analyses: Incentives contracts, asset ownership and job design [J], Journal of Law, Economics and Organization, 1991, 7 (special): 24-52.

[6] Guo-Dong ZHONG, Kun WAN, Rui-Yu LIU. Multi-agent Behavior Analysis and Incentive Mechanism under Multi-relationship [J]. Technology Economics, 2013 (6): 92-97.

[7] Ye-An ZHOU, Zi-Feng SONG. Social Preferences, Information Structure and Contract Selection-A Principal-agent Experiment with Multiple Agents [J]. Economic Research Journal, 2011 (11): 130-144.

[8] Hong-Bin CAI, Qing LIU. Delegation Structure and Incentives: The Case of Multiple Agents [J]. China Economic Quarterly, 2009 (1): 1-22.
[9] Shu-Lin LIU, Xin-Peng JIANG, Qian YU. Research on Board Effectiveness Based on Multi-agent Cooperation Model [J]. Journal of Zhongnan University of Economics and Law, 2015 (2): 150-156.

[10] Hou-Ping TIAN, Chang-Xian LIU, Ya-Jun GUO. Pay scheme designing with multiple agents in production distribution system and analysis on information value [J]. Journal of Management Sciences in China, 2008 (1): 42-48.

[11] Jiao-Jie HAN, Guo-Hua ZHOU, Yan-Lai LI. Research on Multi-Agent Evolutionary Behavior with Bounded Rationality in Project Team Cooperation [J]. Journal of Systems \& Management, 2011 (1): 119-128.

[12] Helmann T F, Murdock K C, Stiglitz J E. Liberalization, moral hazard in banking, and prudential regulation: Are capital requirements enough? [J]. American Economic Review, 2000, 90 (1): $147-165$.

[13] Guo-Hua HUANG, Bang-Yi LI, Tao YE. Research on Collusion of Multiple Agents under Relative Performance Evaluation [J]. Statistics \& Decision, 2006 (3): 13-14.

[14] Jing QIN. Summary of Relative Performance Evaluation Research [J]. Economic Vision, 2013 (2): 102-103.

[15] Milgrom H P. Aggregation and linearity in the provision of intertemporal Incentives [J], Econometrica, 1987, 55 (2): 303-328.

[16] Frederickson J R. Relative performance information: The effects of common uncertainty and contract type on agent effort [J], Accounting Review, 1992, 67 (4): 647-669.

[17] Camara A. The pricing of relative performance based incentives for executive compensation [J]. Journal of Business Finance\& Accounting, 2001, (9-10): 1149-1188.

[18] Holmstrom B, Chen LI. Moral Hazard in Teams [J]. Comparative Economic \& Social Systems, 2017 (1): 31-45. 